Bulletin of Pharmaceutical Sciences
Assiut University
Website: http://bpsa.journals.ekb.eg/
e-mail: bullpharm@aun.edu.eg

\title{
THERAPEUTIC EFFECTS EVALUATION OF VITAMIN E ALONE AND IN COMBINATION WITH RANITIDINE IN STRESS - INDUCED GASTRIC ULCERS IN RATS
}

\author{
Wissam Dahi ${ }^{1}$, Shaza Al laham ${ }^{1}$ and Ahmad Almandili ${ }^{2}$ \\ ${ }^{1}$ Pharmacology \& Toxicology Department, Faculty of Pharmacy, Damascus University, Syria \\ ${ }^{2}$ Pathology Department, Faculty of Dentistry, Damascus University, Syria
}

\begin{abstract}
It is noteworthy to examine the efficacies of vitamin $E$ and its combination with an antagonist of histamine receptor 2 in the treatment of stress gastric ulcers. Animals were divided into 6 groups; group 1 (normal control), group 2 (Cold - restraint stress; CRS), group 3 (ranitidine $20 \mathrm{mg} / \mathrm{kg}$ ), group 4 (vitamin E $100 \mathrm{mg} / \mathrm{kg}$ ), group 5 (ranitidine $10 \mathrm{mg} / \mathrm{kg}+$ vitamin E $50 \mathrm{mg} / \mathrm{kg}$ ), group 6 (ranitidine $5 \mathrm{mg} / \mathrm{kg}+$ vitamin E $50 \mathrm{mg} / \mathrm{kg}$ ). Drugs were administered orally for 7 consecutive days 1 hour after induction of the gastric injury. Rats were sacrificed. The assessment of stomach damage was by body weight observation, macroscopic examinations, histological study, and determination of oxidative stress markers (MDA stomach content and SOD enzyme activity). Present findings showed that the using of vitamin $E$ with ranitidine is dose-dependent, and more effective than using vitamin $E$ alone in the management of stress-induced lesions. Vitamin E caused a remarkable body weight decrease.
\end{abstract}

\section{INTRODUCTION}

Gastric ulcer is a defect in the stomach mucosal barrier that can be formed by Helicobacter pylori, alcohol excessive consumption, nonsteroidal anti-inflammatory drugs (NSAIDs), or exposure to stressful events ${ }^{1}$. After years of investigations, the implication of psychologic factors in the pathogenesis of peptic ulcers is still debated ${ }^{2}$. Stress is developed as a response to multiple severe conditions. It leads to stomach ulceration by irritating the secretion of acid and pepsin, and impairing the mucosal defense ${ }^{3}$. Cold restraint stress (CRS) is the most applicable technique which causes certain gastric lesions in experimental animals ${ }^{4}$.

CRS stimulates the hypothalamuspituitary-adrenal (HPA) axis which activates the release of cortisol. In addition, it disrupts the gastric hormones, and aggravates the generation of free radicals. Moreover, Increased catecholamines levels enhance the expression of inflammatory mediators like tumor necrosis factor- $\alpha(\mathrm{TNF}-\alpha)$ and interlukin6 (IL-6) $^{1}$. overproduction of reactive oxygen species (ROS) causes oxidative stress which leads to distorting the biological tissues and mediates their injury ${ }^{5}$. The mechanism of damage of gastrointestinal cells includes peroxidation of cell membrane lipids, associated with release of intracellular components. Consequently, the inflammatory process in the gastric mucosa will start ${ }^{6}$.

Vitamin $\mathrm{E}$ is known as a powerful antioxidant. It has a beneficial role in preventing oxidation of polyunsaturated fatty acids. In addition, it modulates different mechanisms involved in the origination of gastric lesions ${ }^{7}$.

Ranitidine is the safest drug used to treat gastric ulcers. It acts as a reversible antagonist of $\mathrm{H} 2$ receptors located on the gastric cells. That appears to decrease the impact of gastric offensives such as pepsin and hypersecretion of stomach acid ${ }^{8}$.

The intention was to evaluate the therapeutic effects of vitamin $\mathrm{E}$ and its 
combination with ranitidine on experimentally - induced gastric injury and oxidative damage.

\section{MATERIALS AND METHODS}

\section{Animals}

Male and female wistar albino rats weighing 119-303 $\mathrm{g}$ were purchased from the Scientific Research Center, Damascus, Syria. They were acclimatized for one week before any experimental procedures. The animals were kept at controlled environmental conditions (temperature $23 \pm 2{ }^{\circ} \mathrm{C}$, humidity 55 $\pm 15 \%$, under a $12 \mathrm{hrs}$. light/dark cycle). They had free access to standard rat diet and water. All methods performed in this study were in accordance with the regulatory guidance of the care and use of experimental animals.

\section{Drugs}

Vitamin E acetate SD 50 (BASF) was used in this study. This product can produce a milky suspension in water.

Ranitidine hydrochloride $99.7 \%$ was obtained from ORCHEV PHARMA PVT.LTD, and dissolved in water.

Stock solutions were freshly prepared daily and used for feeding.

\section{Experimental design}

Rats were deprived of food for $24 \mathrm{hrs}$. before the experiment in mesh-bottomed cages to minimize coprophagia, but allowed to free access to water'. All animals were put into individual close-fitting tubular restraint cages of wire mesh. They were placed in a refrigerator at $4 \mathrm{C}^{\circ} \pm 1$ for $2 \mathrm{hrs} .{ }^{10}$. The door of the refrigerator was opened every 0.5 hour for inspection and follow-up 9 .

All experiments were performed during the same time of the day to avoid variations due to diurnal rhythms of putative regulators of gastric functions. All groups -except for the normal control group- were subjected to CRS. After 1 hour, they received either the drugs or vehicles by oral gavage syringe once daily for seven consecutive days.

\section{Treatment Groups}

Animals were randomly divided into 6 groups:

- Group 1. Normal control (NC): (9 rats) received oral vehicle (water).
- Group 2. (CRS): (8 rats) received oral vehicle (water).

- Group 3. (R20): (8 rats) received ranitidine $(20 \mathrm{mg} / \mathrm{kg})$ [3].

- Group 4. (E100): (9 rats) received Vitamin E (100 mg/kg) [11].

- Group 5. (R10 + E50): (8 rats) received ranitidine $(10 \mathrm{mg} / \mathrm{kg})+$ Vitamin $\mathrm{E}(50$ $\mathrm{mg} / \mathrm{kg}$ ).

- Group 6. (R5 + E50): (9 rats) received ranitidine $(5 \mathrm{mg} / \mathrm{kg})+$ Vitamin $\mathrm{E}(50$ $\mathrm{mg} / \mathrm{kg}$ ).

\section{Tissue collection and preparation}

After seven days of treatment with the appropriate drug for each group, animals were sacrificed. A midline incision was made. Stomachs were isolated and opened along the greater curvature, then washed by saline. Gastric mucosa was examined by naked eye and magnifying lens. A precise evaluation of the lesions was made, then each specimen was fixed in $13 \%$ formalin. Stomach tissue samples were stored at $-80^{\circ} \mathrm{C}$ for further analysis.

\section{Clinical findings}

Rats were checked daily for body weight, behavioral changes, food intake, rectal bleeding, and stool consistency. Body weight was measured at regular time intervals from day 0 to 7 . Changes of body weight (\%) were calculated.

\section{Macroscopic scoring}

Number and severity of gastric lesions were scored according to the following system $^{12}: 0:$ no lesion, $1:$ mucosal edema and petechiae, 2 : (1-5) small lesions (1-2 mm), 3 : $>5$ small lesions or 1 intermediate lesion (3-4 $\mathrm{mm}), 4: \geq 2$ intermediate lesions or 1 gross lesion (> $4 \mathrm{~mm}$ ), and 5 : perforated ulcers.

Each lesion was considered as an ulcer to calculate the following parameters:

Degree of ulceration $=$ total ulcer score $/$ No. of animals ulcerated ${ }^{13}$.

ulcer index $(\mathbf{U I})=$ total ulcer score / No. of animals in group.

It was expressed as: UI \pm SD (standard deviation) ${ }^{12}$.

Curative ratio $=[1-(\mathrm{UI}$ treated/UI ulcerated $) \times$ $100]^{13}$. 


\section{Histopathological observations}

A portion of the stomach of each rat was fixed in $13 \%$ formalin. The specimens were embedded in paraffin wax and cut into sections of $5 \mathrm{~mm}$ thickness. The sections were stained with hematoxylin and eosin ( $\mathrm{H}$ and $\mathrm{E})$ dye for the histopathological examination. The histological sections were assessed by an experienced pathologist who was blinded to the treatment for: grade and type of inflammation (score: $0-4$ ), presence of epithelial erosions (score: 0-2), presence of epithelial ulcers (score: 0-1), edema in the lamina propria (score: 0-1), blood vessels congestion (score: 05), epithelial atrophy (score: 0-1), and epithelial hyperplasia (score: 0-1), yielding a maximum total score of $15^{14}$.

\section{Biochemical assays}

Precisely weighed tissues of stomach were homogenized in cold phosphate-buffered saline $(\mathrm{pH} 7.4,50 \mathrm{mmol})$ to prepare $10 \%$ tissue homogenate. The resultant suspension was divided into two parts. The first one was used for the determination of malondialdehyde (MDA). The second part was centrifuged for $20 \mathrm{~min}$ at $4{ }^{\circ} \mathrm{C}$, and the supernatant was used for SOD activity measurement.

\section{Estimation of lipid peroxidation}

Detection of malondialdehyde (MDA) (the end product of lipid peroxidation) by a colorimetric reaction with thiobarbituric acid (TBA), is a highly sensitive indicator for evaluating the mucosal injury induced by ROS in gastric tissues exposed to oxidative stress ${ }^{15}$. In brief, $0.5 \mathrm{ml}$ of stomach tissue homogenate was mixed with $2 \mathrm{ml}$ of TBA reagent containing $(0.375 \%$ TBA, $15 \%$ trichloroacetic acid and $0.25 \mathrm{~N} \mathrm{HCl}$ ). Samples were boiled for 15 min, cooled and centrifuged. The absorbance of the supernatant was spectrophotometrically read at $532 \mathrm{~nm}$, using an extinction coefficient of $1.56 \times 10^{5} / \mathrm{M} \mathrm{cm}$.

Final Concentration of unknown sample/gram tissue $=100 \times \mu \mathrm{M} \quad$ LPO equivalent/gram tissue ${ }^{16}$.

\section{Estimation of superoxide dismutase (SOD) activity}

The procedure is as follows: First, a certain amount of pyrogallol solution $(60 \mathrm{mmol}$ in $1 \mathrm{mmol} \mathrm{HCl}, 37^{\circ} \mathrm{C}$ ) was well mixed with
Tris- $\mathrm{HCl}$ buffer $(0.05 \mathrm{M}, \mathrm{pH}$ 7.4) containing 1 $\mathrm{mM}$ Na2EDTA. The volume was adjusted to $3000 \mu \mathrm{l}$ using the buffer. The A325 nm value of the mixture without a sample was measured every $30 \mathrm{~s}$ for $5 \mathrm{~min}$ at $37{ }^{\circ} \mathrm{C}$. Second, we repeated the exact previous step with the addition of the sample. Enzyme activity, which matches the amount of enzyme that inhibits the auto-oxidation of pyrogallol by $50 \%$, was calculated and expressed per mg of protein ${ }^{17}$.

\section{Statistical analysis}

Data analyses were performed using Prism (version 8) statistical package. Data were presented as means \pm SEM. Different groups were compared using one-way analysis of variance (ANOVA) followed by Sidak test for multiple comparisons of parametric data, and Kruskal-Wallis test followed by Dunn test for multiple comparisons of non-parametric and parametric data that have shown abnormal distribution. $\mathrm{P}$ values $<0.05$ were considered statistically significant.

\section{RESULTS AND DISCUSSION}

\section{Results \\ Clinical findings, general observation, and body weight changes}

After $24 \mathrm{~h}$ of exposure to CRS, most animals developed diarrhea and progressively body weight loss, accompanied with weakness and decreased food intake. All these symptoms began to decrease gradually in groups (R20) and (R10 + E50) starting from day 3. However, groups CRS, (E100), and (R5 + E50) did not show any obvious improvement. Some rats died during the experiment. That is likely due to hemorrhagic or perforated stomach lesions.

At the end of the experiment, body weight of CRS group was reduced by $(-1.51 \%)$ compared to $\mathrm{NC}$ group, which revealed body weight increase by $(+2.82 \%)$ with no statistical significance $(p=0.1654)$.

Groups (R20) and (R10 + E50) revealed an increase in body weight by $(+0.18 \%$, $+0.75 \%$, respectively), but with no statistical significance compared to CRS group ( $p=$ $0.5942, p=0.4775$ respectively). Meanwhile, body weight of group (R5 + E50) was less by ($1.93 \%)$, but with no statistical significance compared to CRS group ( $p=0.9399$ ). 
Group (E100) revealed a significant decrease in body weight by $(-10.76 \%)$ compared to CRS group at ( $p=0.0078$ ). (figure. $1)$.

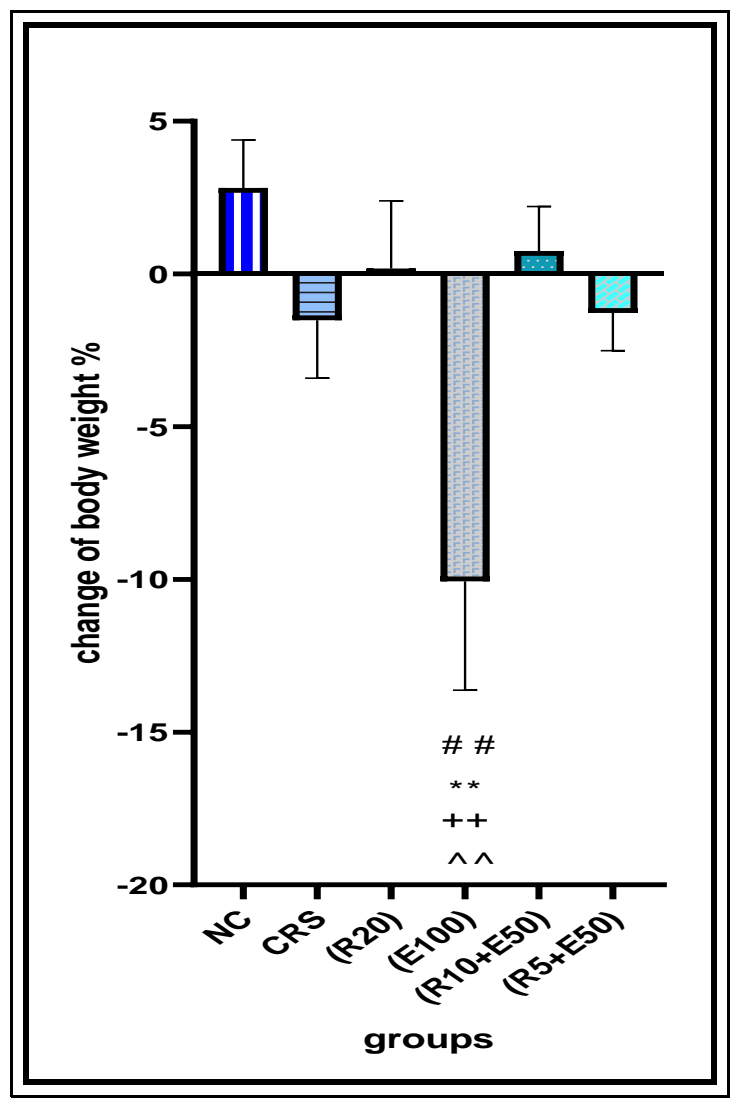

Fig. 1: Effect of ranitidine, vitamin $E$, and their combination on body weight in CRS exposed rats. Data were expressed as mean \pm S.E.M

** $\mathrm{P}<0.01$ compared to CRS group. $++\mathrm{P}<$ 0.01 compared to (R20) group. ${ }^{\wedge} \wedge \mathrm{P}<$ 0.01 compared to (R10 + E50) group. \#\# $\mathrm{P}<0.01$ compared to (R5 + E50) group.

\section{Macroscopic scoring}

NC group stomachs apparently showed healthy mucosa in most samples, with no swelling or hemorrhage. Two samples showed some tiny pinpoint lesions. In contrast, CRS group showed notable severe injuries in the form of dark reddish hemorrhagic lesions, with variable forms and sizes. Also, there was a generalized hyperemia in the gastric mucosa. CRS significantly increased the ulcer index $(P<$ 0.0001) compared to $\mathrm{NC}$ group.

(R20) group stomachs showed fewer ulcers with less marked hyperemia and moderate mucosal injuries, with statistical significance compared to CRS group ( $P=$ 0.0056). $59.375 \%$ curative ratio was recorded.

Vitamin E effectively decreased the ulcer index compared to CRS group $(P=0.0006)$. $66.68 \%$ curative ratio was recorded. The combination of ranitidine $(5 \mathrm{mg} / \mathrm{kg})$ and vitamin E $(100 \mathrm{mg} / \mathrm{kg})$ ameliorated the morphological changes compared to CRS group) $P=0.009)$. However, this decrease was not significant compared to (R20), (E100), and $(\mathrm{R} 10+\mathrm{E} 50)$ groups $(p=0.0803, P=0.4258, p=$ 0.0509 respectively). $69.445 \%$ curative ratio was recorded.

$(\mathrm{R} 10+\mathrm{E} 50)$ group had the best outcome in all measured parameters compared to CRS group) $P<0.0001)$, but this improvement was not significant compared to (R20), (E100) groups $(p=0.6003, P=0.23380$ respectively). Curative ratio significantly increased compared to $(\mathrm{R} 5+\mathrm{E} 50)$ group $(93.75 \%)$. (Table. 1 , figure. 2, 3)

Table.1: Effect of ranitidine, vitamin E, and their combination on gastric parameters in stress - induced ulcer in rats

\begin{tabular}{|c|c|c|c|c||}
\hline Parameter & $\begin{array}{c}\text { Ulcer } \\
\text { Severity }\end{array}$ & $\begin{array}{c}\text { Ulceration } \\
\text { Degree }\end{array}$ & Ulcer index \pm SD & $\begin{array}{c}\text { Curative } \\
\text { ratio }\end{array}$ \\
\cline { 1 - 4 } NC & 3 & 1.5 & $0.333 \pm 0.707$ & - \\
\hline CRS & 32 & 4 & $4 \pm 0 * * *$ & - \\
\hline R20 & 13 & 2.6 & $1.625 \pm 1.74 \wedge \wedge$ & $59.375 \%$ \\
\hline E100 & 12 & 3 & $1.333 \pm 1.803 \wedge \wedge \wedge$ & $66.68 \%$ \\
\hline R10+E50 & 2 & 1 & $0.25 \pm \cdot . \leqslant 74^{\wedge \wedge \wedge \wedge}$ & $93.75 \% @$ \\
\hline R5+E50 & 11 & 1.2222 & $1.222 \pm 0.667^{\wedge \wedge}$ & $69.445 \%$ \\
\hline
\end{tabular}



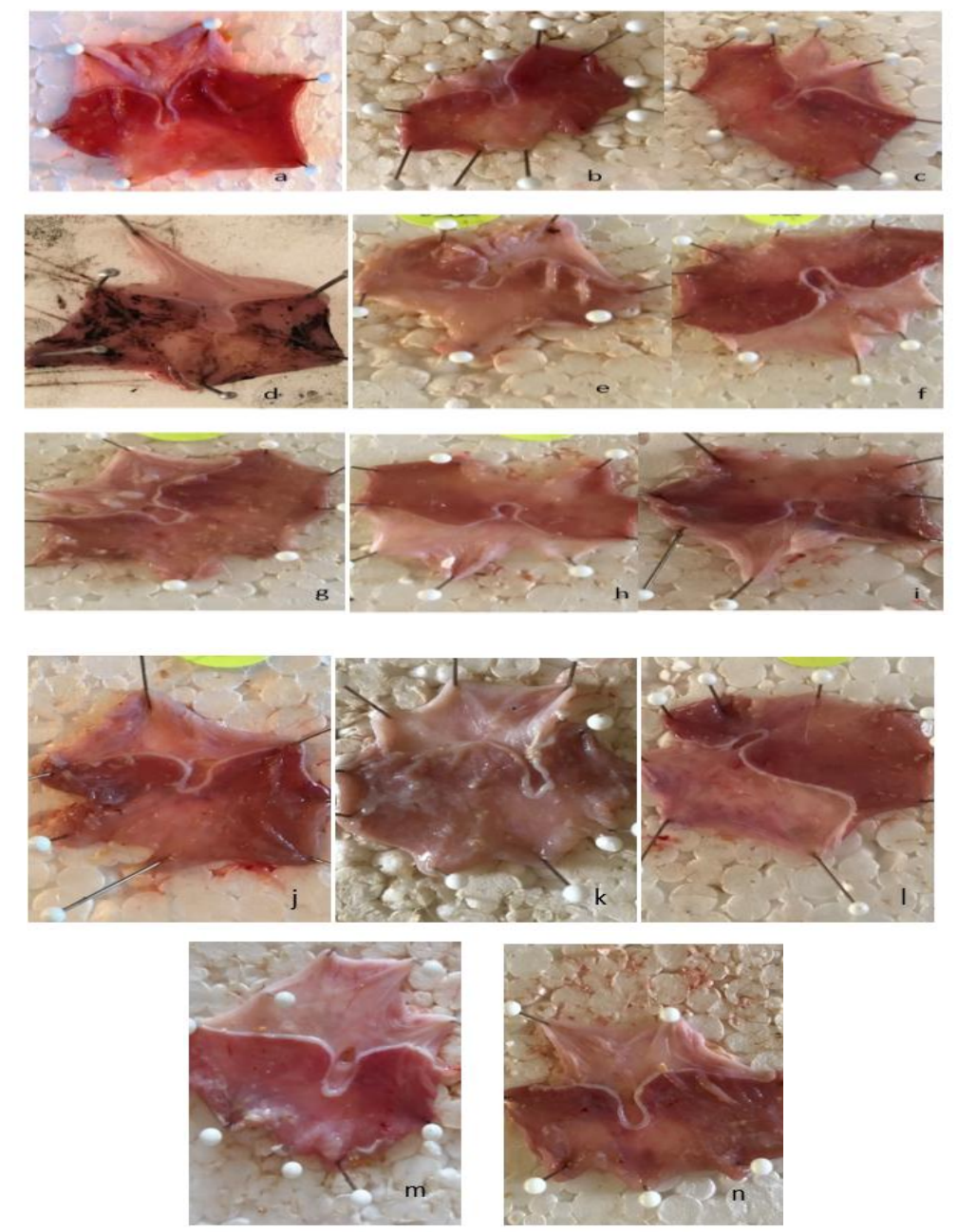

Fig.2: Macroscopic morphology changes in the gastric mucosa. a, NC group (grade0); b, NC group (grade1); c, NC (grade2); d, CRS group (grade 4); e, (R20) group (grade 0); f, (R20) group (grade 1); g, (R20) group (grade 4); h, (E100) group (grade 0); I, (E100) group (grade 1); j, (E100) group (grade 4); k, (R10+E50) group (grade 0); 1, (R10+E50) group (grade 1); m, (R5+E50) group (grade 1); n, (R5+E50) group (grade $3)$.

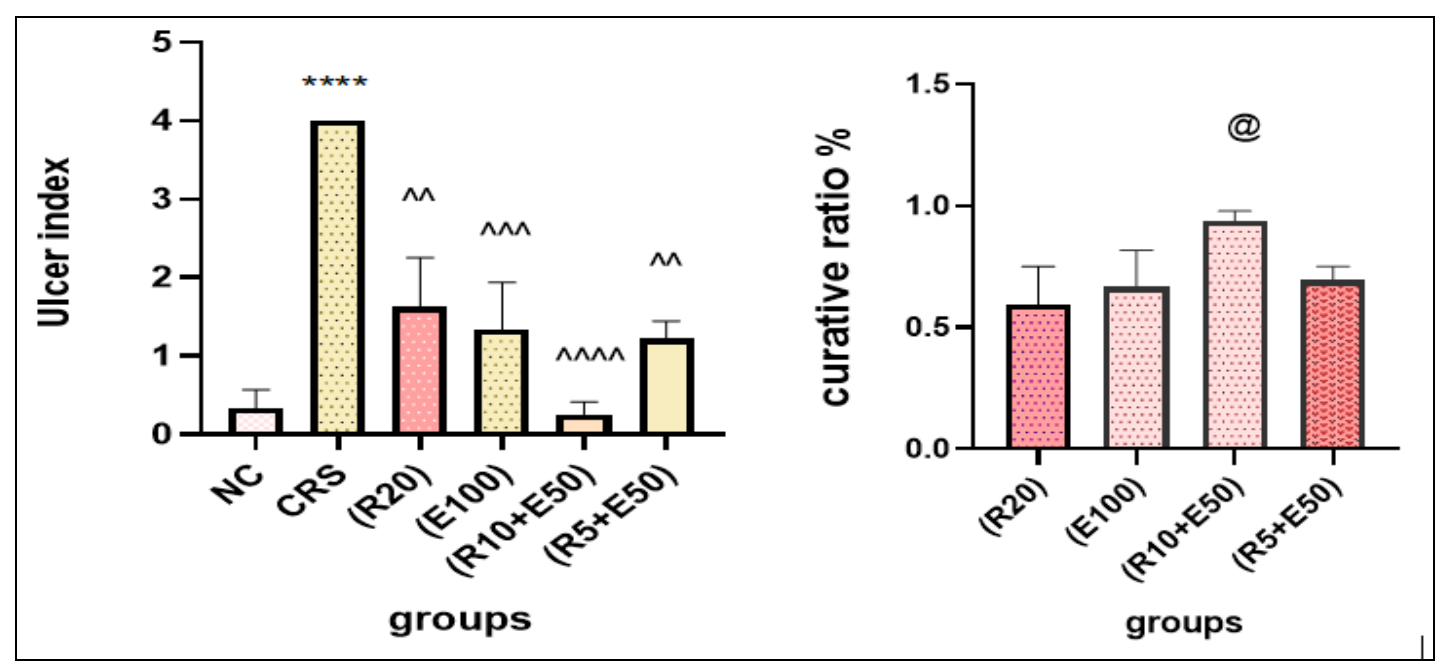

Fig.3: Effect of ranitidine and vitamin $\mathrm{E}$ and their combination on UI and curative ratio $* * * * \mathrm{p}<0.0001$ compared to NC group. ${ }^{\wedge \wedge \wedge \wedge} \mathrm{p}<0.0001$ compared to CRS group. ${ }^{\wedge \wedge \wedge} \mathrm{p}<0.001$ compared to CRS group. ${ }^{\wedge \wedge} \mathrm{p}<0.01$ compared to CRS group. @ $\mathrm{p}<0.05$ compared to (R5+E50) group. 


\section{Histopathological study}

Histological evaluation of gastric walls in stress - induced ulcerated rats had manifested an extensive damage to the gastric mucosa (deep erosions and ulcers), severe blood vessels congestion, edema in the lamina propria, inflammatory cells infiltration in the submucosal layer, and disorganized cells (architecture, shape, thickness), with high scores of microscopic damage when compared to NC group $(P<0.0001)$. Administration of ranitidine $(20 \mathrm{mg} / \mathrm{kg})$ revealed a significant reduction in the severity of mucosal stomach damage when compared to CRS group ( $P=$ 0.0014). Significant histologic improvement was observed in (E100) group when compared to CRS group $(P=0.0005)$. Meanwhile, rats in $(\mathrm{R} 10+\mathrm{E} 50)$ group showed a significant reduction in the histopathological score when compared to CRS group $(P<0.0001)$. similarly, rats in (R5 + E50) group revealed a significant reduction in the severity of injury when compared to CRS group $(P=0.0012)$. (table. 2, figure. 4)

Table.2: Effect of ranitidine, vitamin E, and their combination on the microscopic score in stress induced gastric ulcer in rats

\begin{tabular}{|c|c|c|c|c|c|c|c|c|}
\hline group & $\begin{array}{c}\text { Edema } \\
\text { (score0 } \\
-1)\end{array}$ & $\begin{array}{c}\text { epithelial } \\
\text { Hyperplasia } \\
\text { (score 0-1) }\end{array}$ & $\begin{array}{c}\text { Blood } \\
\text { vessels } \\
\text { congestion } \\
\text { (score 0-5) } \\
\end{array}$ & $\begin{array}{c}\text { Epithelial } \\
\text { erosion } \\
\text { (score0-2) }\end{array}$ & $\begin{array}{l}\text { Epithelial } \\
\text { ulceration } \\
\text { (score 0-1) }\end{array}$ & $\begin{array}{l}\text { Inflammati } \\
\text { on } \\
\text { infiltration } \\
\text { (score } 0-4 \text { ) }\end{array}$ & $\begin{array}{c}\text { epithelial } \\
\text { Atrophy } \\
\text { (score 0-1) }\end{array}$ & $\begin{array}{c}\text { Total } \\
\text { Scores } 15\end{array}$ \\
\hline NC & $0(0-1)$ & $0(0-1)$ & $4(4-4)$ & $0(0-1)$ & $0(0-0)$ & $1(0-3)$ & $0(0-0)$ & $6(5-9)$ \\
\hline CRS & $\begin{array}{c}\text { 1(0-1) } \\
\# \# \#\end{array}$ & $1(0-1)$ & $5(5-5) \# \#$ & $2(0-2)$ & $0(0-1) \#$ & $3(0-4)$ & $0(0-1) \#$ & $\begin{array}{l}\text { 11(11-12) } \\
\# \# \#\end{array}$ \\
\hline $\mathbf{R 2 0}$ & $1(0-1)$ & $0(0-1)$ & $4(2-4) * * *$ & $1(0-2)$ & $0(0-1) *$ & $1(0-2) * *$ & $0(0-1) * *$ & $7(5-9) * *$ \\
\hline E100 & $1(0-1)$ & $0(0-0) * *$ & $4(2-4) * * * *$ & $1(0-1)$ & $0(0-0) * *$ & $1.5(0-4)$ & $0(0-1) * * *$ & $7(2-8) * * *$ \\
\hline $\begin{array}{l}\text { R10 + } \\
\text { E50 }\end{array}$ & $0(0-1) *$ & $0.5(0-1)$ & $2(0-4) * * * *$ & $1(0-1)$ & $0(0-0) * *$ & $1(0-3) *$ & $0(0-0) * * * *$ & $3.5(1-9)^{* * * * *}$ \\
\hline $\begin{array}{l}\text { R5 + } \\
\text { E50 }\end{array}$ & $1(1-1)+$ & $0(0-1)$ & $4(2-4) * * * *$ & $1(0-1)$ & $0(0-1)^{*}$ & $2(0-2) \bullet$ & $0(0-0) * *$ & $7(4-9) * *$ \\
\hline
\end{tabular}

The table shows median values followed by minimum and maximum scores (in brackets). \#\#\# p<0.0001 \#\# $\mathrm{p}<0.001$ \#\# $\mathrm{P}<0.01$ \# $\mathrm{P}<0.05$ compared to NC group. **** $\mathrm{p}<0.0001 * * * \mathrm{P}<0.001 * * \mathrm{P}<0.01 * \mathrm{P}<0.05$ compared to CRS group. $\bullet \mathrm{P}<0.05$ compared to (R20) group. + $\mathrm{P}<0.05$ compared to (R10+E50) group. 

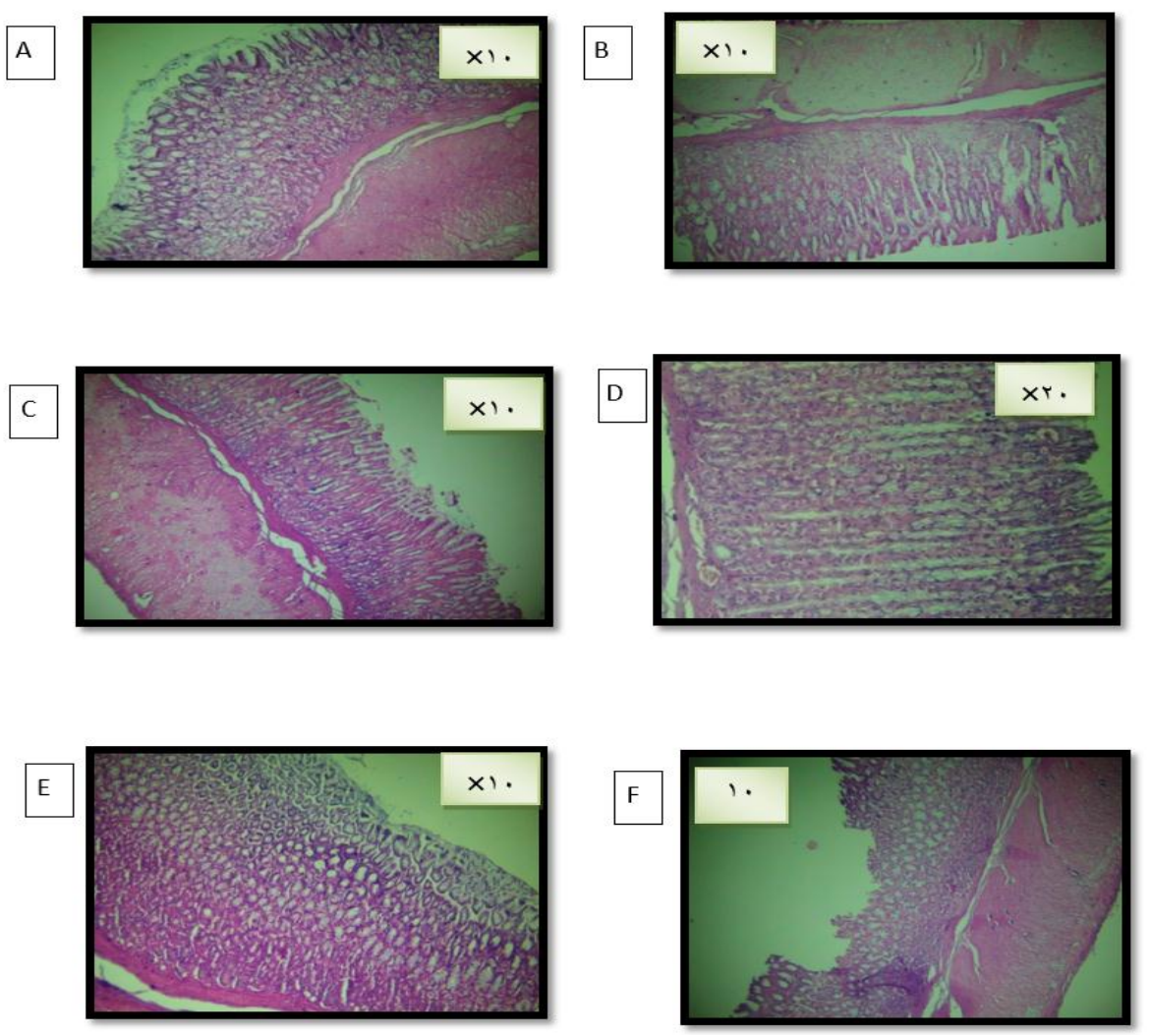

Fig. 4: Histological appearance of stomach tissue sections. A, NC group (grade 5); B, CRS group (grade 10); C, (R20) group (grade 5); D, (E100) group (grade 6); E, (R10+E50) group (grade 3); F, (R5+E50) group (grade 6)

\section{Biochemical Investigations}

CRS induced oxidative cascade in rats' stomachs; it was evaluated by lipid peroxides (LPO) levels and SOD activity.

\section{Stomach MDA content}

There was a significant elevation in stomach MDA levels in rats exposed to CRS compared to NC group $(P<0.0001)$. These levels were significantly lower in groups treated with ranitidine alone (R20) and the 2 combination groups $(\mathrm{R} 10+\mathrm{E} 50)$ and $(\mathrm{R} 5+$ E50) compared to CRS group $(P=0.0002, \mathrm{P}<$ $0.0001, \mathrm{P}=0.0031$ respectively). A statistically significant difference was found when comparing the combination group (R10+E50) (with the higher dose of ranitidine) with single treatment groups (R20), (E100), and the other combination group (R5+E50) (with the lower dose of ranitidine $)(P=0.0310, P<0.0001$, $\mathrm{P}=0.0016$ respectively). However, rats received vitamin $\mathrm{E}$ alone (E100 group) substantially showed decreased MDA levels compared to (R20) group $(P=0.0397)$, but with no statistical significance compared to CRS group $(P=$ 0.0558 ). These results are shown in (figure. 4$)$.

\section{Stomach superoxide dismutase (SOD) activity}

Exposure to stress significantly decreased SOD activity in stomach tissues compared to NC group $(P<0.0001)$. Administration of vitamin $\mathrm{E}$ alone or in combination with ranitidine $(\mathrm{E} 100, \mathrm{R} 10+\mathrm{E} 50$, and $\mathrm{R} 5+\mathrm{E} 50$ groups) substantially increased the enzyme activity compared to CRS group $(P<0.0001$, $\mathrm{P}<0.0001, \quad \mathrm{P}=0.0031$ respectively). Meanwhile, administration of ranitidine alone (R20 group) elevated the enzyme activity, but not in a significant manner compared to CRS group) $\mathrm{P}=0.0850)$. A statistically significant difference was found when comparing the combination group (R10 + E50) with (R20) and $(\mathrm{R} 5+\mathrm{E} 50)$ groups $(P<0.0001, P=0.0017$ respectively), but there was no statistical significance when compared to (E100) group $(P=0.9252)$. on the other hand, we recognized a significant difference when comparing (R5 + E50) group with (R20), (E100) groups $(P<0.0001, \quad P=0.0009$ respectively $)$. These results are shown in (figure.4). 


\section{Discussion}

One common health problem related to stress is the formation of acute gastric lesions, better known as stress ulcers ${ }^{5}$. Cheng et al, and Perez et al. demonstrated that the pathogenesis of stress ulcers is multifactorial and includes high inflammatory and oxidative damage, reduced gastric prostaglandin synthesis, and inhibition of mucosal growth and proliferation $^{18}$. Pattanaprateep et al. declared that different models of acute and chronic cellular insults are mediated by free radicals. Hence, they promote the degradation of the mucosal epithelial basement membrane, and cause further tissue harm ${ }^{19}$.

Various experimental models of ulceration mimicking the disease in human have been developed to test the potential beneficial effects of various drugs. One of the common employed methods is CRS synergistically with fasting in rats ${ }^{20}$. Therefore, we applied this technique in our study.

Our results confirmed that CRS produces oxidative stress status associated with severe inflammatory response in rats. That was evidenced by body weight loss, reduction in food intake, gastric mucosal injury, and changes in biomarkers which include elevation in MDA levels, and depleted antioxidant enzymes activities, such as SOD. There was a reduction in body weight of CRS group by $154 \%$ compared to NC group which exhibited a slight increase in body weight. Macroscopic results revealed characteristic acute gastric lesions such as mucosal edema, patchy hemorrhagic ulcers and erosions. That appeared by a significant increase in ulceration parameters, which is in agreement with many studies, i.e. the study of Bahadir et $\mathrm{al}^{21}$. Furthermore, the lesions are associated with a significant increase in lipid peroxides levels by $155 \%$, and a significant depletion in SOD activity by $81 \%$ compared to NC group. That was in harmony with the findings of Elsaed et al. They attributed the decreased SOD activity and LPO levels increase to the formation of ROS which mediate the cascade of stressinduced mucosal injury ${ }^{22}$.

Previous data indicated that antioxidants like vitamin $\mathrm{E}$ healed some, but not all of the inflammatory stimuli in this model.

Gastric acid exacerbates the damage of gastric mucosa induced by other agents. Furthermore, it can convert superficial erosions into deeper necrosis, and inactivates some of the growth factors that are vital for the repair of mucosal cells. Ranitidine was shown to inhibit histamine and decrease gastric acid secretion ${ }^{3}$.
The present study evaluates the magnitude of the participation of vitamin $\mathrm{E}$ with other treatments used in gastropathy, such as ranitidine. Biochemical and morphological examinations were undertaken to investigate the therapeutic effects of vitamin $\mathrm{E}$ alone and in combination with ranitidine in stressinduced ulcers.

Our study results revealed that administration of vitamin $E$ alone caused a considerable loss of body weight by $613 \%$ compared to NC group. That can be explained by the study of Alcalá et al. They demonstrated that vitamin $\mathrm{E}$ reduces triglycerides levels, and enhances adipose tissue capability to increase their storage limits. As a result, circulating free fatty acids will not be then redirected to other tissues $^{23}$. Furthermore, treatment with vitamin E markedly reduced gastric mucosal damage that stress induced. This finding gets along with the finding of Nur Azlina et al. ${ }^{24}$. They attributed that to the capacity of vitamin $E$ to inhibit lipid peroxidation and scavenge free radicals. Regarding the anti-oxidant effects of vitamin $\mathrm{E}$, it decreased gastric MDA content by $20 \%$, and significantly improved the activity of SOD by $414 \%$ compared to CRS group. That is in concordance with the study of Shah et $\mathrm{al}^{25}$.

In comparison, rats treated with ranitidine alone showed body weight improvement by $112 \%$, and a significant decrease in lipid peroxides levels by $43 \%$. Also, SOD activity increased by $63 \%$ compared to CRS group. Ching et al. showed that $\mathrm{H} 2$ blockers are very strong hydroxyl radical scavengers. Also, Ahmadi et al. observed that ranitidine exhibits a strong, dose-dependent antioxidant activity ${ }^{26}$. According to these studies, the therapeutic effects of $\mathrm{H} 2$ blockers in peptic ulcers may be correlated to their antiradical capacity. Moreover, we observed a significant improvement in the macroscopic and microscopic scores compared to CRS group; these results are in agreement with the findings of Chandranath et al. They declared that ranitidine has a protective effect against CRSinduced gastric ulcers ${ }^{3}$. Another study represented that ranitidine exerts powerful scavenging effects towards hypochlorous acid and monochloramine, which are released from inflammatory cells such as neutrophils ${ }^{26}$.

The effects of the combination ranitidine $(10 \mathrm{mg} / \mathrm{kg})$ and vitamin E $(50 \mathrm{mg} / \mathrm{kg})$ on macroscopic injury (lowest UI and best curative ratio), microscopic scores, and oxidative stress were superior to those of every agent alone, or to the other combination group (R5+E50). These values achieved significance 
compared to CRS group; SOD activity increased by $410 \%$, and LPO levels decreased by $66 \%$. Rats in the group (R10 + E50) showed an increased body weight by $149 \%$. Whereas, the combination (R5 + E50) decreased rats body weight by $168 \%$, but not in a significant manner compared to CRS and (R20) groups. However, this decrease was significantly less than the effect of vitamin $E$ alone.

Consistently, the rats treated with ranitidine $(5 \mathrm{mg} / \mathrm{kg})$ and vitamin $\mathrm{E}(50 \mathrm{mg} / \mathrm{kg})$ showed a remarkable improvement in macroscopic scores, microscopic damage, and oxidative stress parameters; SOD activity increased by $284 \%$, and Stomach MDA content reduced by $28 \%$ compared to CRS group.

The rates of healing seem to be faster in the presence of ranitidine as evidenced in the results of the two combination groups. So, the drug appears to play a crucial dose- dependent therapeutic role in this issue.

\section{Conclusion}

The findings of this study indicate that vitamin $\mathrm{E}$ is effective in the management of stress-induced gastric ulcers, alone and combined with ranitidine. However, this combination has shown a greater efficacy than the single treatment. That is possibly imputed to the consequent synergistic effects, through attenuating the inflammatory cascade, inhibition of tissue oxidative stress, and promotion of mucosal barrier repair.

\section{REFERENCES}

1. SM. Elshazly, DM. Abd El Motteleb and IA. Ibrahim, "Hesperidin protects against stress induced gastric ulcer through regulation of peroxisome proliferator activator receptor gamma in diabetic rats", Chemico-biological interactions., 291, 153-161 (2018).

2. CH. Stephen, DS. Pardi and JJ. Poterucha, "Mayo clinic gastroenterology and hepatology board review", 3th Ed., Rochester, Minnesota, 53-97 (2008).

3. SI. Chandranath, SM. Bastaki, A. D'Souza, A. Adem and J. Singh, "Attenuation of stress-induced gastric lesions by lansoprazole, PD-136450 and ranitidine in rats", Molecular and cellular biochemistry, 349 (1), 205-212 (2011).
4. AM. Rashad, GH. Heeba and SH. Hamad, "Age-dependent Role of Cilostazol on Cold Restraint Stress induced Gastric Ulceration in Female Rats", Journal of Clinical \& Experimental Investigations., 10 (3),1-10 (2019).

5. MF. Azlina, MS. Qodriyah, MN. Akmal, IA. Ibrahim and Y. Kamisah, "In vivo effect of Piper sarmentosum methanolic extract on stress-induced gastric ulcers in rats", Archives of medical science: AMS., 15 (1), 223-231 (2019).

6. KV. Hatware, S. Sharma, K. Patil, M. Shete, S. Karri, et al., "Evidence for gastroprotective, anti-inflammatory and antioxidant potential of methanolic extract of Cordia dichotoma leaves on indomethacin and stress induced gastric lesions in Wistar rats", Biomedicine \& Pharmacotherapy., 103, 317-325 (2018).

7. Y. Kamisah, HM. Qodriyah, KH. Chua and MF. Nur Azlina, "Vitamin E: A potential therapy for gastric mucosal injury", Pharmaceutical biology, 52 (12), 15911597 (2014).

8. M. Jafar, AA. Mohsin, MS. Khalid, AM. Alshahrani, FS. Alkhateeb, et al., "Ranitidine hydrochloride stomach specific bouyantmicrosponge: Preparation, in-vitro characterization, and in-vivo antiulcer activity", Journal of Drug Delivery Science and Technology, 55, 101453 (2020).

9. SS. Kamar, NS. Latif, MF. Elrefai, SN. Amin, "Gastroprotective effects of nebivolol and simvastatin against cold restraint stress-induced gastric ulcer in rats", Anatomy \& Cell Biology, 53 (3), 301-312 (2020).

10. AR. Al-Moutairy, M. Tariq, "Effect of vitamin $\mathrm{E}$ and selenium on hypothermic restraint stress and chemically-induced ulcers", Digestive diseases and sciences, 41 (6), 1165-1171 (1996).

11. IB. Turkyilmaz, ZM. Coskun, S. Bolkent and R. Yanardag, "The effects of antioxidant combination on indomethacininduced gastric mucosal injury in rats", Cellular and Molecular Biology., 65 (3), 76-83 (2019).

12. I. Arsić, A. Žugić, DR. Antić, G. Zdunić, D. Dekanski, et al., "Hypericum Perforatum 
L. Hypericaceae/Guttiferae Sunflower, Olive and Palm Oil Extracts Attenuate Cold Restraint Stress-Induced Gastric Lesions", Molecules, 15 (10), 6688-6698 (2010).

13. PA. Nwafor, FK. Okwuasaba and LG. Binda, "Antidiarrhoeal and antiulcerogenic effects of methanolic extract of Asparagus pubescens root in rats", Journal of Ethnopharmacology, 72 (3), 421-427 (2000).

14. W. F. Li, D. J. Hao, T. Fan, H. M. Huang, H. Yao, et al., "Protective effect of chelerythrine against ethanol-induced gastric ulcer in mice", ChemicoBiological Interactions, 208, 18-27 (2014).

15. H. Zemmouri, O. Sekiou, S. Ammar, A. El Feki, M. Bouaziz, et al., "Urtica dioica attenuates ovalbumin-induced inflammation and lipid peroxidation of lung tissues in rat asthma model", Pharmaceutical biology, 55 (1), 15611568 (2017).

16. NR. Patil, VP. Rasal and RH. Malabade, "Screening of mandarin oil on indomethcin induced inflammatory bowel disease in wistar rats", Indian Journal of Pharmaceutical Education and Research., 48 (Supplementary), 1-6 (2014).

17. X. Li, "Improved pyrogallol autoxidation method: a reliable and cheap superoxidescavenging assay suitable for all antioxidants", Journal of Agricultural and Food Chemistry, 60 (25), 6418-6424 (2012).

18. S. Lu, D. Wu, G. Sun, F. Geng, Y. Shen, et al., "Gastroprotective effects of Kangfuxin against water-immersion and restraint stress-induced gastric ulcer in rats: roles of antioxidation, anti-inflammation, and pro-survival", Pharmaceutical biology, 57 (1), 770-777 (2019).

19. KV. Hatware, S. Sharma, K. Patil, M. Shete, S. Karri, et al., "Evidence for gastroprotective, anti-inflammatory and antioxidant potential of methanolic extract of Cordia dichotoma leaves on indomethacin and stress induced gastric lesions in Wistar rats", Biomedicine \& Pharmacotherapy., 103, 317-325 (2018).
20. AM. Rashad, GH. Heeba and SH. Hamad, "Age-dependent Role of Cilostazol on Cold Restraint Stressinduced Gastric Ulceration in Female Rats", Journal of Clinical \& Experimental Investigations, 10 (3), 1-10 (2019).

21. E. Bahadir, M. Bulut, B. Kabayuka, ES. ŞENKAL, A. Avlac, et al., "The effect of simvastatin pretreatment on stress-induced gastric ulcer in rats", Marmara Medical Journal., 29, 1-7 (2016).

22. WM. Elsaed, AM. Alahmadi, BT. AlAhmadi, JA. Taha and RM. Tarabishi, "Gastroprotective and antioxidant effects of fluvoxamine on stress-induced peptic ulcer in rats", Journal of Taibah University medical sciences, 13 (5), 422431 (2018).

23. M. Alcalá, I. Sánchez-Vera, J. Sevillano, L. Herrero, D. Serra et al., "Vitamin E reduces adipose tissue fibrosis, inflammation, and oxidative stress and improves metabolic profile in obesity", Obesity., 23 (8):1598-1606 (2015).

24. MF. Nur Azlina, K. Rubaizah, M. Siti Muliana and MI. Nafeeza, "Modulation of restraint induced gastric oxidative changes in rats by tocotrienol and tocopherol",

IJP-International Journal of Pharmacology, 5 (1), 58-64 (2009).

25. D. Shah, M. Nitin, AS. Rao, "Gastroprotective effect of selected antioxidants, vitamins and minerals in ethanol induced ulcer model in rats", Journal of Pharmacy Research, 11 (3), 201-209 (2017).

26. A. Ahmadi, MA. Ebrahimzadeh, S. Ahmad-Ashrafi, M. Karami, MR. Mahdavi, et al., "Hepatoprotective, antinociceptive and antioxidant activities of cimetidine, ranitidine and famotidine as histamine $\mathrm{H} 2$ receptor antagonists", Fundamental \& clinical pharmacology., 25 (1), 72-79 (2011). 


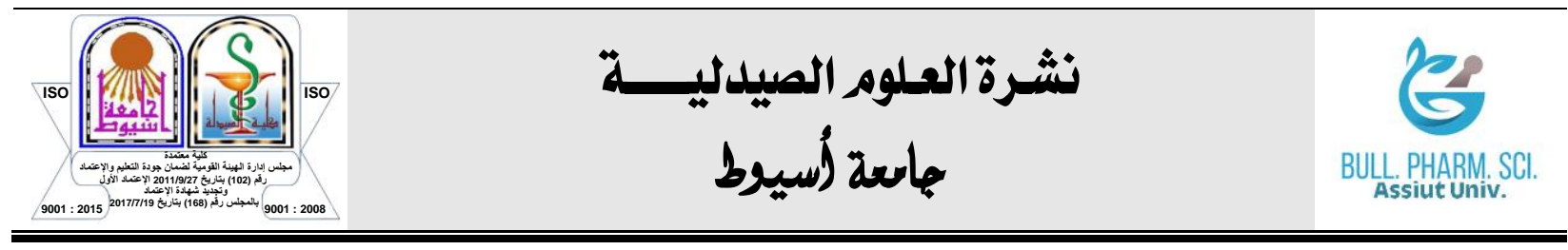

\section{تقييم التأثيرات العلاجيّة للفيتامين E منفرداً ، وبالمشاركة مع الرانيتيدين في

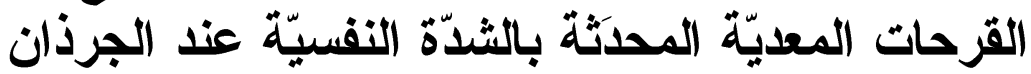

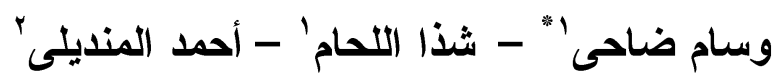

$$
\text { ' قسم الأدوية و السموم ، كلية الصيدلة ، جامعة دمشق ، سوريا }
$$

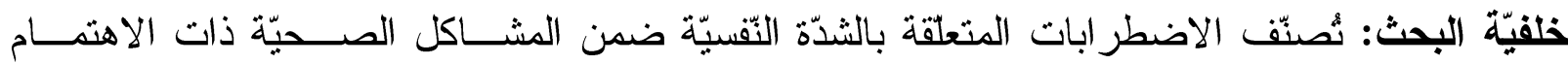

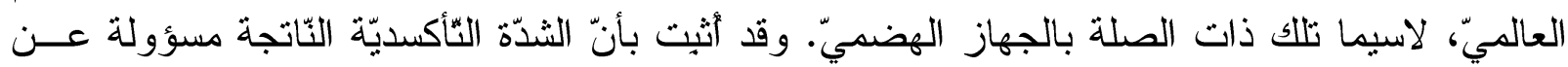

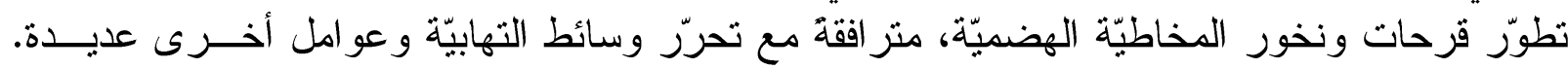

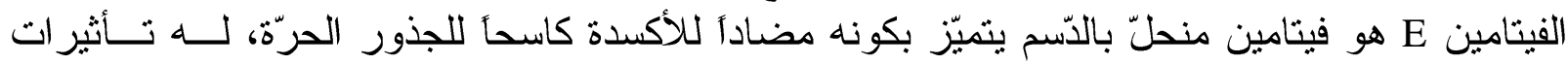

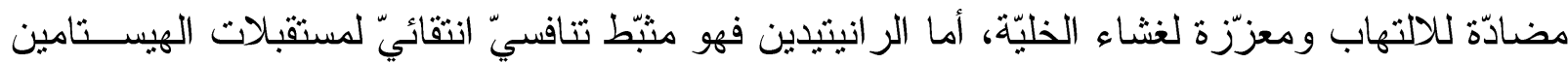
H2 الموجودة في الخلايا المعديّة الجداريّة. لمدئ.

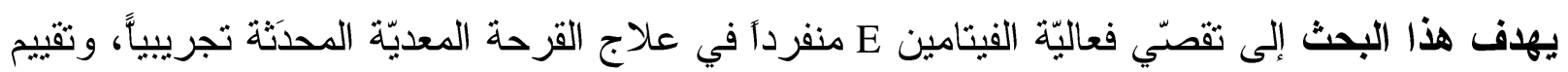

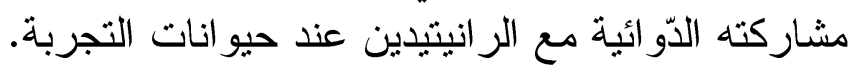

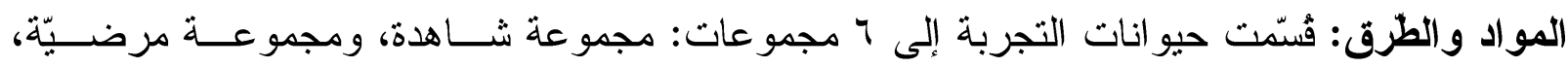

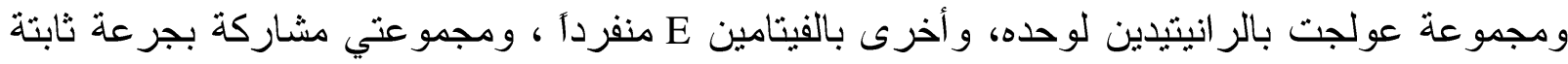

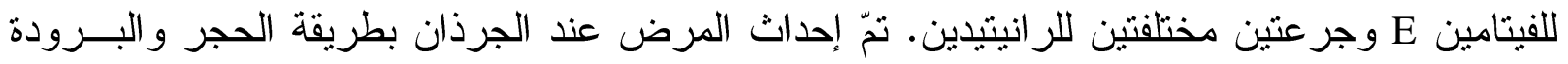

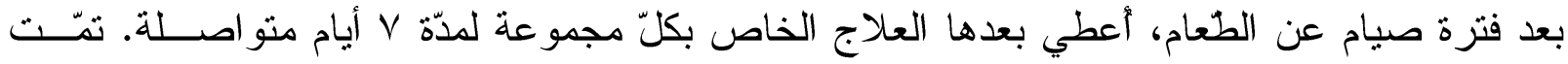

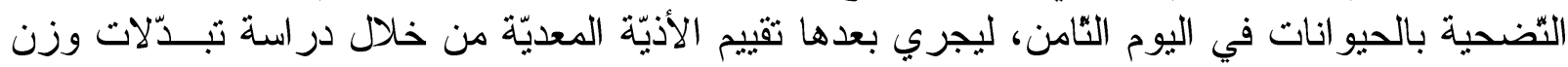

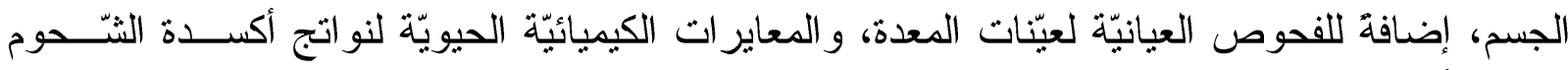
وفعاليّة أنزيم Superoxide dismutase (SOD) في المعدة.

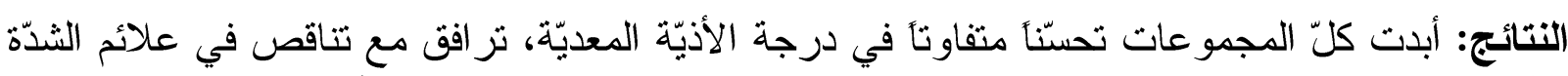

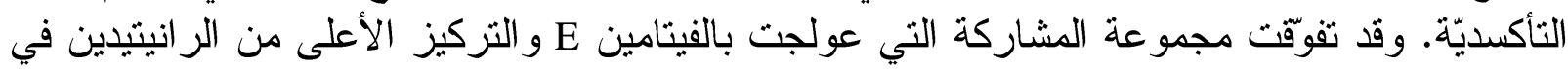

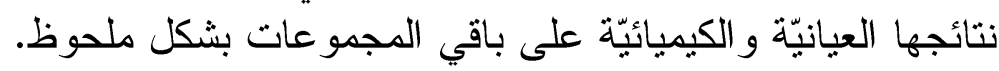

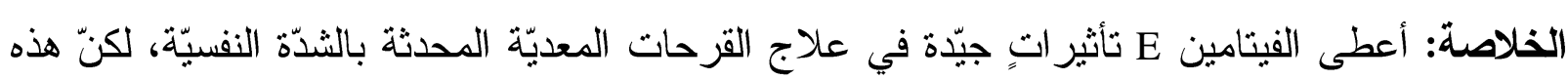

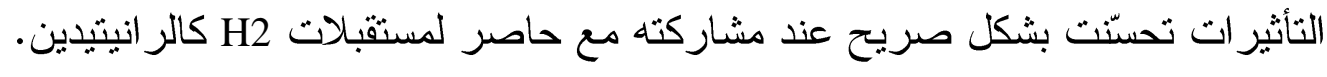

